\title{
Demographics of Patients Using Harmful/Traditional Eye Medications in Anya Specialist Eye Clinic, Umuahia, South East Nigeria
}

\author{
Kalu Anya ${ }^{1}$, , Nwachukwu Kennedy Ugo ${ }^{2}$, Otuka Olufunmi Ijeoma ${ }^{1}$, Eweputanna Lisa ${ }^{3}$ \\ ${ }^{1}$ Ophthalmology Unit, Department of Surgery, Abia State University Uturu, Uturu, Nigeria \\ ${ }^{2}$ Department of Ophthalmology, University of Calabar Teaching Hospital Calabar, Calabar, Nigeria \\ ${ }^{3}$ Radiology Unit, Department of Surgery, Abia State University Uturu, Uturu, Nigeria
}

Email address:

dranyak@gmail.com (K. Anya),justkenn2000@yahoo.com (N. K. Ugo), elshaddai_2005@yahoo.com (O. O. Ijeoma), eweputannalisa@gmail.com (E. Lisa)

${ }^{*}$ Corresponding author

\section{To cite this article:}

Kalu Anya, Nwachukwu Kennedy Ugo, Otuka Olufunmi Ijeoma, Eweputanna Lisa. Demographics of Patients Using Harmful/Traditional Eye Medications in Anya Specialist Eye Clinic, Umuahia, South East Nigeria. International Journal of Ophthalmology \& Visual Science. Vol. 5, No. 3, 2020, pp. 80-83. doi: 10.11648/j.ijovs.20200503.13

Received: August 30, 2020; Accepted: September 28, 2020; Published: October 12, 2020

\begin{abstract}
Background: Traditional eye medication (TEM) is common in Sub-Saharan Africa especially as it is part of the well practiced Traditional Alternate and Complementary Medicine. Despite several observed harmful effects and documented ocular morbidity from TEM, and the fact that the TEMs have no scientific background to their use, they are applied to the eyes as medication. This study is to look at the demographics of the patients with a history of TEM use presenting to a private clinic in South East Nigeria, with a view of targeted health education and promotion. Method: A retrospective review of patients' hospital records, seen in Anya Specialist Eye Clinic, Umuahia Abia State Nigeria, between January 2019 and June 2020 was done. Data from patients' records who self-reported to have used Harmful/Traditional Eye Medications before presentation at the clinic, during the period under consideration were selected, and their social/demographic characteristics extracted. Results: A total of 42 subjects with TEM use were recorded. There were 27 males $(64.3 \%)$ and 15 females $(35.7 \%)$ with age range from 0 to 70 years. Their educational levels were; no formal education $(26.1 \%)$, primary $(24 \%)$, secondary $(28.5 \%)$ and tertiary (21.5\%). More than $57 \%$ of the subjects were peasant farmers or unemployed, while $24 \%, 4.7 \%, 4.7 \%$ and $2.4 \%$ were traders, students, retired civil servants and teachers respectively. Conclusion: Farmers and unemployed subjects were more likely to use harmful TEM than other occupations. Surprisingly educational level did not significantly influence the rate of use of TEM. The assumption that individuals with higher educational status have a lower risk of TEM use may be erroneous. There should be an increase in awareness of the dangers of TEM use to the general public.
\end{abstract}

Keywords: Traditional Eye Medication, Demographics, South East Nigeria, Umuahia

\section{Introduction}

Traditional eye medication (TEM) can be defined as any unorthodox medicine or practices that are applied to the eye or consumed in order to achieve a therapeutic or beneficial effect on an ocular disorder $[1,2]$. It has been documented that there is no scientific background to the use of these therapies, and most often it leads to damage to the eye or further loss of vision. Thus they are better described as harmful traditional eye medication (HTEM) [2-4]. Traditional Eye Medications are often biologically-based therapies like crude or partially processed organic (plant and animal products) or in-organic (chemical) substances. [5] It also includes mechanical or thermal devices applied to the eye or its adnexae by traditional practitioners or lay people. [2] TEM is highly prevalent in sub-Saharan Africa especially 
in countries where Traditional Alternate and complementary medicine (TCAM) is recognised, though largely unregulated [6].

Some researchers have mentioned the need to differentiate HTEM from adverse effects of eye medication. Adverse effects of ocular medications are unwanted occurrences from the use of scientifically proven beneficial treatments [2].

Some of the known HTEM include cassava extract, human/cow urine, breast milk, plant leaf extracts, onion juice, kerosene, brake-fluid, and other traditional concoctions [7]. Some practices like 'couching' of the crystalline lens and cautery to the eyelid, termed harmful practices are also included. Some of these substances are known to be toxic to the eye while others have caused serious infections in the eye because of their high level of micro-organism contamination [8].

TEM use is very common because as it is seen to be more readily accessible, available and affordable than orthodox medicine. Another reason why TEM are used is that most orthodox eye care practices are in the urban areas while most of the population reside in rural areas where the practice of TEM is more common. Furthermore there is this belief in the potency of herbal medications, which are also believed to have little or no side effects $[4,7]$. These beliefs have led to increased patronage of herbal products, concoctions and mixtures which have unknown but highly variable dosages, with attendant serious and often fatal outcomes. Attempts to discourage people from patronizing these TEM and other harmful traditional practices are often unsuccessful. For these reasons, some public health specialist have suggested the training of the traditional medicine practitioners to deliver primary eye care in places where eye care is not readily available $[5,9]$.

Some documented complications of TEM use include eyelid burns, loss of eyelashes, cicatricial symblepharon, corneal melting and opacities, corneal ulcers, thermal and chemical burns to the ocular surface etc [7, 10-12].

There are variable risk factors and demographics associated with the use of HTEM but most literature have found a positive relationship between low socioeconomic/poor educational background and increased used of HTEM [3, 5, 9].

The purpose of this study is to examine the demographics of patients presenting to Anya Specialist Eye Clinic with a history of TEM. This study was carried out because a lot patients with history of TEM seen in Anya Specialist Eye Clinic were noticed to have higher educational background than should be expected from previous studies.

\section{Methods}

The study was a cross-sectional descriptive study. A retrospective review of patients' hospital records, seen in Anya Specialist Eye Clinic, Umuahia Abia State Nigeria, between January 2019 and June 2020. Anya Specialist Eye clinic is a private high-volume centre providing comprehensive and tertiary eye care services to a population of over 4 million, and also attracting patients from all other states in Nigeria.

Data from patients' records who self-reported to have used Harmful/Traditional Eye Medications at any point during the period under consideration were selected, and their social/demographic characteristics extracted.

The educational levels and occupations of guardians were used for subjects who were minors (age below 18 years).

The data was inputted into Microsoft Excel and represented as tables and graphs.

\section{Results}

A total of 42 subjects with HTEM use were recorded. Their characteristics are presented in the tables and figures below.

Table 1. Age Distribution of subjects.

\begin{tabular}{lll}
\hline Age (years) & Frequency & Percentage (\%) \\
\hline Below 1 & 1 & 2.4 \\
$1-10$ & 10 & 24 \\
$11-20$ & 1 & 2.4 \\
$21-30$ & 8 & 19 \\
$31-40$ & 9 & 21.4 \\
$41-50$ & 6 & 14.3 \\
$51-60$ & 4 & 9.5 \\
$61-70$ & 3 & 7.1 \\
Total & 42 & 100 \\
\hline
\end{tabular}

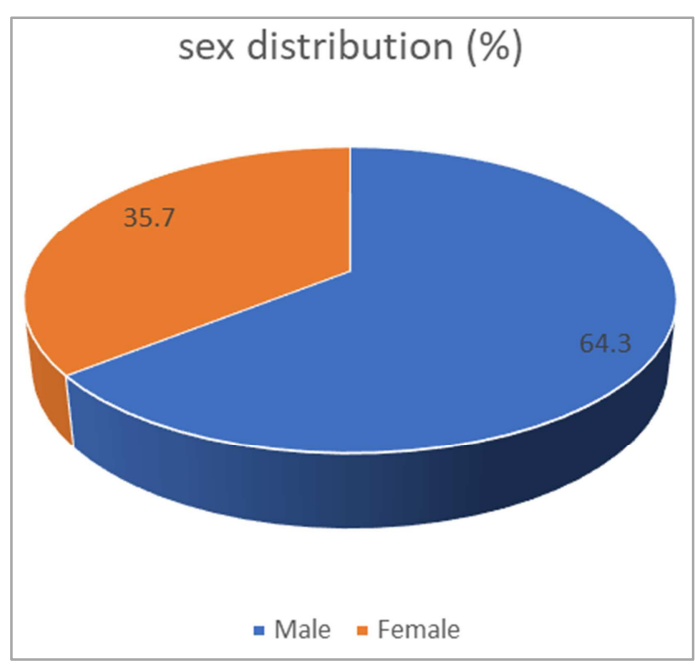

Figure 1. Sex Distribution of subjects.

Table 2. Occupation of subjects.

\begin{tabular}{lll}
\hline Occupation & Frequency & Percentage (\%) \\
\hline Artisans & 3 & 7.1 \\
Traders/Business & 10 & 24 \\
Farmers & 11 & 26.1 \\
Students & 2 & 4.7 \\
Unemployed/Applicants & 13 & 31 \\
Teachers & 1 & 2.4 \\
Retired civil servant & 2 & 4.7 \\
Total & 42 & 100 \\
\hline
\end{tabular}




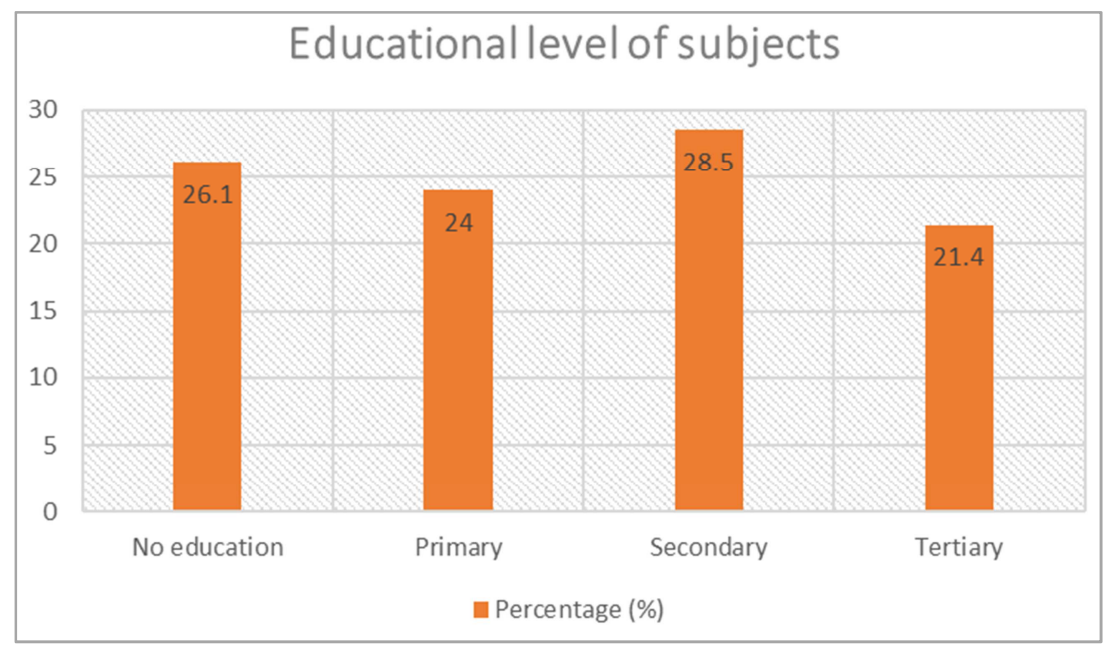

Figure 2. Educational level of subjects.

\section{Discussion}

The prevalence and incidence of TEM use in Nigeria has varying figures from different studies. It ranges from as low as $1.72 \%, 5.9 \%$ and $48.7 \%$ (from Nigerian studies) $[3,4,10]$ to as high as $49 \%$ and $62.3 \%$ in Tanzania and Oman respectively [13]. These variations are likely as a result of differences in study population, sample size and sampling methods.

Although this study should have ideally been a populationbased study, Anya Specialist eye clinic (where this study was done) is a private high volume centre (about 2000 patients seen and 650 surgeries done in 2019 alone) [14] attending to a high proportion of ophthalmic patients from South-East Nigeria. It is likely that a sample of the patients attending this clinic can reveal a lot about health-seeking attitudes of people from South East Nigeria.

It was previously thought that high use of TEM was associated with high levels of ignorance and poor educational background, but recent literature has found increasing trends despite improved access to information and modern education [3].

There were more males $(64.3 \%)$ than females $(35.7 \%)$ with a male to female ratio of $1.8: 1$. This suggests that males are almost twice likely to use TEM than females, though the small number of subjects in this study precludes this assertion. It could also be due the more daring nature of the males. Some other studies reported a higher use of TEM in females [1, 3, 7]; though only the study done by Eze et al [3] found a significant difference. One study reported higher use in males [10], while others concluded that there was no signiciant difference $[11,12]$.

The age group with the highest frequency of TEM use is the 1-10 years group, followed closely by the $31-40$ and 21 30 (Table 1). Similar hospital-based studies from the southern part of Nigeria reported highest frequency of TEM use among an older population. Nwosu et al [1] reported that those above 50 years were more likely to use TEM, while
Eze et al [3] and Achigbu et al [5] found the highest frequency among the 61-70 years age group. These differences may be due to demographic differences in the population of patients presenting to the different eye hospitals. However the common finding in all (including index study) is that more than $50 \%$ of the subjects are between the ages of 21 and 60 which represents the most active workforce of the population. Other studies have also noticed that the use of TEM was most common among the workforce age group [3, 7]. It can be argued that this age group are more prone to injuries, conditions and ocular exposures that warrants the use of TEM.

Surprisingly, our study shows that educational level does not seem to significantly affect the rate of use of HTEM. As seen from Figure 2, the rate of use of HTEM was largely similar across all educational backgrounds. About $50 \%$ of those that used HTEM had at least a secondary level of education. Although those with tertiary level of education had the lowest frequency $(21.4 \%)$ of TEM use, there was no significant statistical difference between the educational levels. It is usually assumed that people with tertiary level of education will desist from using non-scientific unproven methods to treat a delicate organ like the eye. A similar study from South East Nigeria also found no statistical difference between educational status and TEM use, though the frequency was lower with tertiary levels of education [5]. A systematic review on traditional, complementary and alternative medicine use in Sub-Saharan Africa found an inconsistent relationship between educational level and use of traditional medicine [6].

However, the occupation of subjects seem to influence the rate of HTEM use as this was seen commonly among farmers and unemployed subjects. It can be reasoned that farmers are more likely to use HTEM since they live closer and have easier access to traditional herbal practitioners, usually reside far from city centre where most eye clinics are situated, and have less access to orthodox eye care centres. The unemployed subjects may have financial constraints in accessing conventional treatments, thus more likely to use 
the more affordable and easily available TEM. Most of the cited studies agreed with this finding that farmers and unemployed subjects were more likely to use TEM $[3,4,6$, 7].

\section{Conclusion}

The use of HTEM is fairly common in Nigeria. It is seen across all age groups, educational level and occupations. Educational level does not seem to significantly influence the rate of use of HTEM in South East Nigeria but unemployed person's and farmers are more likely to use HTEM than other listed occupations. It is an erroneous assumption that the risk of TEM use and its attendant ocular morbidity is more common among those with little or no formal education. This study has shown that formal education is not a deterrent to use of harmful TEM, so specific awareness should be created about the dangers of TEM use to the general public, and not just to the less educated.

Limitations

1. The small number of the sample may not reveal the true relationship between demographics and TEM use.

2. The study is a hospital-based study; a population-based study would give conclusions that are more applicable to the rest of the population.

\section{References}

[1] Nwosu, S. N. N. \& Obidiozor, J. U. Incidence and risk factors for traditional eye medicine use among patients at a tertiary eye hospital in Nigeria. Niger. J. Clin. Pract. 14, 405-407 (2011).

[2] Foster, A. \& Johnson, G. G. Traditional eye medicines good or bad news? Br. J. Ophthalmol. 78, 1994 (1994).

[3] Eze, B. I., Chuka-okosa, C. M. \& Uche, J. N. Traditional eye medicine use by newly presenting ophthalmic patients to a teaching hospital in south-eastern Nigeria : socio-demographic and clinical correlates. BMC Complement. Altern. Med. 9, 940 (2009).

[4] Kayoma, D. \& Ukponmwan, C. DETERMINANTS OF THE USE OF TRADITIONAL EYE MEDICATION IN A SEMIURBAN COMMUNITY IN SOUTHERN NIGERIA. $J$. West african Coll. Surg. 6, (2016).

[5] Achigbu, E. O. \& Achigbu, K. I. Traditional eye medicine use among ophthalmic patients attending a secondary health care center in Southeast Nigeria. Port Harcourt Med. J. 11, 79-83 (2017).

[6] James, P. B., Wardle, J., Steel, A. \& Adams, J. Traditional, complementary and alternative medicine use in Sub-Saharan Africa : a systematic review. BMJ Glob. Heal. 3, (2018).

[7] Ajite, K. O. \& Fadamiro, O. C. Prevalence of Harmful / Traditional Medication Use in Traumatic Eye Injury. Glob. J. Health Sci. 5, 55-59 (2013).

[8] Aghaji, A., Ezeome, I. \& Ezeome, E. Evaluation of Content and Cost of Traditional Eye Medication in a Resource-poor Country - Implications for Eye Care Practice and Policy. Niger. J. Clin. Pract. 21, 1514-1519 (2018).

[9] Ebeigbe, J. A. Traditional eye medicine practice in BeninCity, Nigeria. South African Optom. 72, 167-172 (2013).

[10] Osahon, A. Consequences of traditional eye medication in U. B. T. H. Benin City. Niger. J. Ophthalmol. 3, 51-54 (1995).

[11] Courtright, P., Lewallen, S., Kanjaloti, S. \& Divala, D. Traditional eye medicine use among patients with corneal disease in rural Malawi. $B r J$ Ophthalmol. 78, 810-812 (1994).

[12] Prajna, V., Pillai, M., Manimegalai, I. \& Srinivasan, M. use of Traditional eye medications by corneal ulcer patients presenting in a hospital in South India. Indian J Ophthalmol 47, 15-18 (1999).

[13] Mselle, J. Visual impact of using traditional medicine on the injured eye in Africa. Acta Trop. 70, 185-192 (1998).

[14] Unpublished. Anya Specialist Eye Clinic Report. (2019). 